\title{
Preparing for Disaster: Establishing an Ag Pass Program in Your Community
}

MATTHEW SHAPERO,

University of California

Cooperative Extension

Area Livestock and Range

Advisor in Ventura and

Santa Barbara Counties

MAX MORITZ, University of California Cooperative

Extension Wildfire

Specialist in the Bren

School of Environmental

Science and Management at UC Santa Barbara

\section{INTRODUCTION/THE THREAT}

$\mathrm{n}$ the last several years, Californians have witnessed some of the largest and most severe wildfires in the history of their state, with growing numbers of homes and lives lost. The causes include changing environmental conditions and expanding human development on fire-prone landscapes (Schoennagel et al. 2017; Radeloff et al. 2018). Low-impact fires of the past were generally easier to control, but today many fires qualify as disasters. To counter this trend, California is increasingly emphasizing comprehensive approaches to reducing risk before fires are ignited. These approaches include removing hazardous fuels, retrofitting structures to reduce ignition vulnerabilities, and planning for evacuation (Moritz et al. 2014). Funds are increasingly available to support these activities, particularly in the wildland-urban interface - that is, areas where urban development meets and intermingles with natural flammable vegetation (Radeloff et al. 2005).

Awareness is growing of fire's impacts on specific commercial agricultural commodities-for example, wine grapes (Chong and Cleary 2012; Krstic et al. 2015) -but such

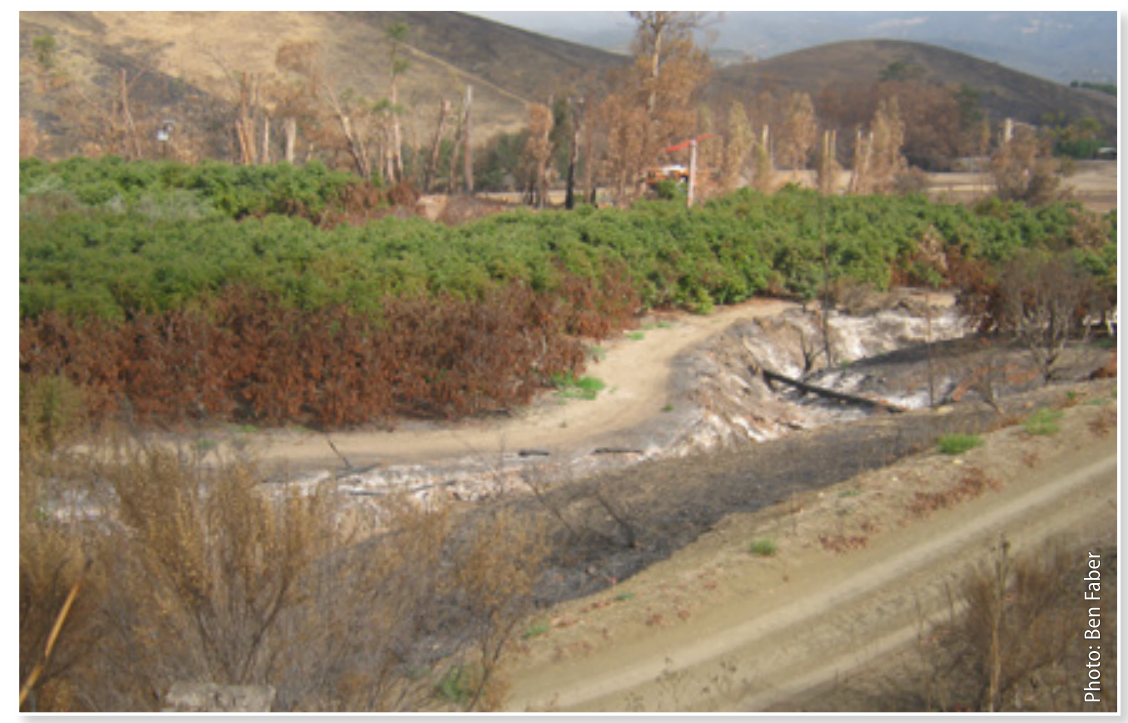

Figure 1. In December of 2017, this avocado orchard in Ventura County buffered the spread of wildland fire out of a riparian area. awareness is not the norm. When disasters threaten communities, agriculture is typically underserved because orchards, livestock, and crops are not high-priority items for firefighters. Their focus is on lives and structures (largely, residential structures). This leaves a gap in protection for important agricultural resources. Farmers may be left to fend for themselves, even though farm fields-because of their position in the landscape and their foliar moisture (Aquilué et al. 2019) —-may create buffer zones that reduce wildfire impacts in surrounding areas and provide welcome relief to firefighters (fig. 1). Livestock producers may likewise be left to fend for themselves even though ranch pastures-where grazing leads to lower fuel loads-can also create buffers (Nader et al. 2007). Agricultural practitioners have therefore had to seek innovative ways to protect their property and livelihoods. In particular, they have sought access to their land during wildfire evacuations, when certain areas are closed to the general public (fig. 2). 


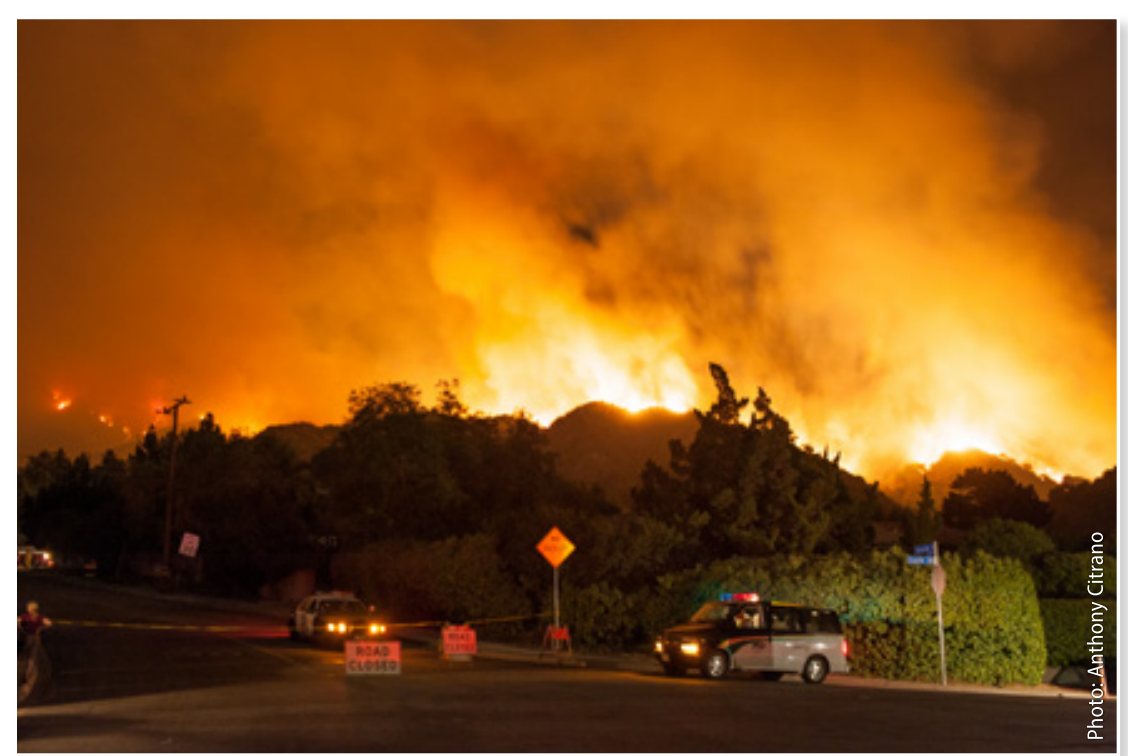

Figure 2. Neighborhood evacuated during the 2009 Station Fire in Los Angeles County. As indicated by signs and the presence of law enforcement, it is typically not possible for the general public to enter an area once it has been evacuated. Photo republished under Creative Commons license CC BY-NC-DN 2.0.

Figure 3. Example of a local press pass. Although the California Penal Code (409.5) allows the press to report in close proximity to natural hazard events, access is dependent on safety conditions and is given at the discretion of law enforcement at the site. Source: Burn Cycle Project.

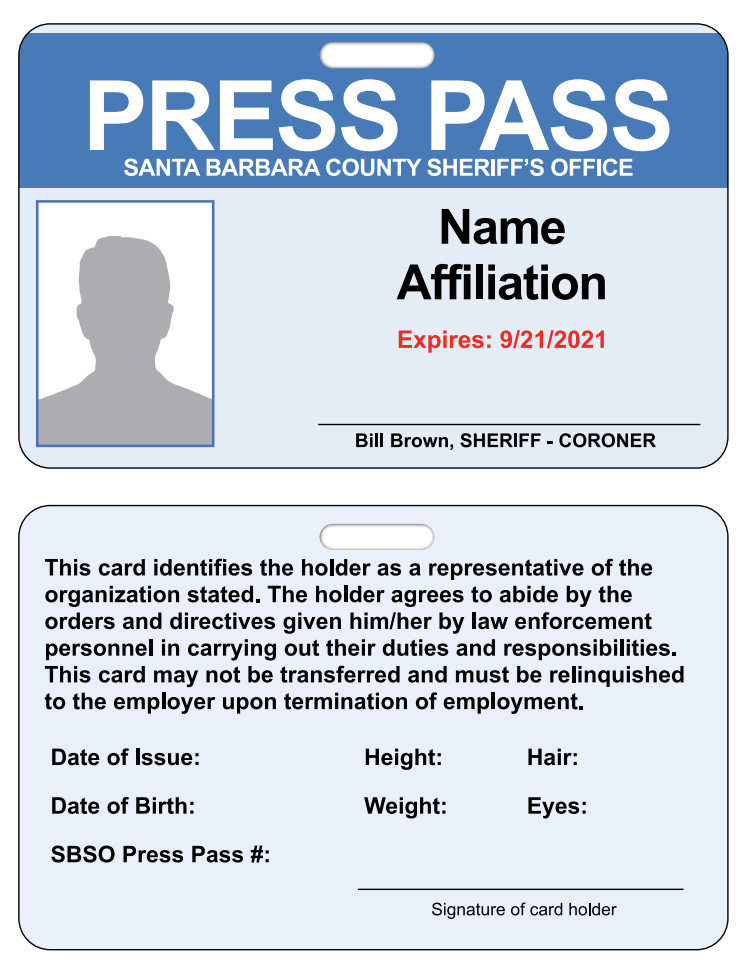

Multiple precedents exist for authorized access behind evacuation lines. Photographers and reporters are regularly issued press passes for the purpose of reporting in close proximity to natural hazard events (fig. 3), as allowed under the California Penal Code. Another example is animal rescue situations, in which volunteers receive training and authorization to move pets, horses, and other livestock out of evacuated areas. Recently, private firefighting forces have been allowed to work in evacuated areas to protect specific homes (when, for example, insurance companies pay for such services). In all these cases, access behind evacuation lines is allowed at the discretion of the authorities managing the situation. Decisions are based on safety conditions at the time. It is crucial in all these cases that those who may seek access to an evacuation zone establish communication-before a crisis-with all relevant local agencies so that authorities understand and support the process. Establishing communication before a crisis is likewise crucial for those who may need access to their agricultural lands.

What follows is a detailed description of how to establish a county-based program that grants agriculturalists special access to their farms or ranches during disaster. The document is intended to provide a blueprint for how communities across California might approach such a program, but it recognizes that the structure and organization of any such program will ultimately depend upon the specific resources, politics, and relationships within any one community.

\section{WHY ESTABLISH AN AG PASS PROGRAM?}

The purpose of a county-based "Ag Pass" program is to identify owner-operators of commercial farms and ranches, along with their employees, to firefighting personnel, California Highway Patrol officers, sheriff's deputies, and other emergency personnel. Possession of an Ag Pass during a wildfire or similar disaster allows the agriculturalist access to areas that may otherwise be restricted to the public so that the agriculturalist can 1) protect or care for agricultural assets (such as by irrigating crops or feeding, watering, and transporting livestock) or 2) provide auxiliary support to emergency personnel (such as identification of access roads and water points). 


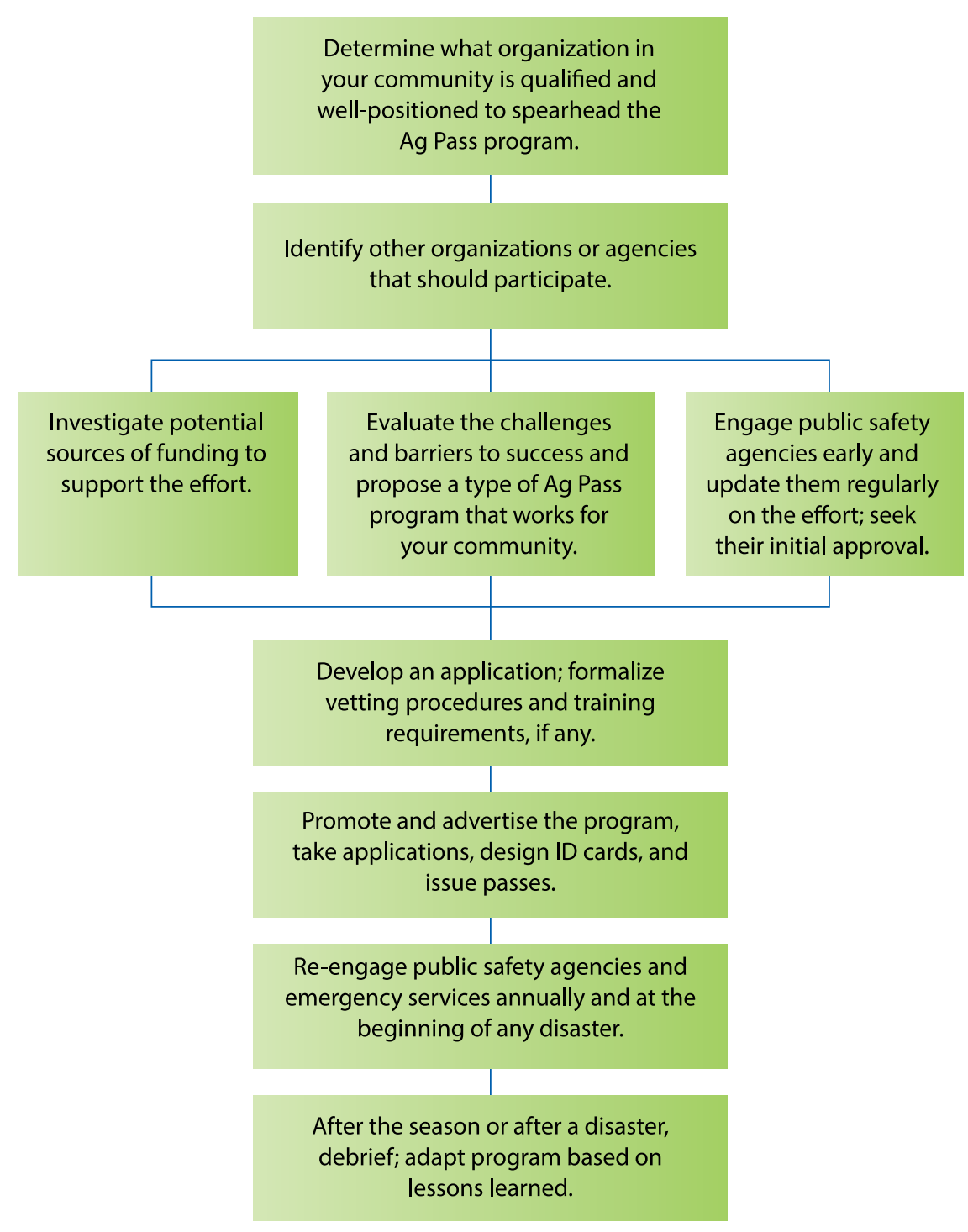

Figure 4. Step-by-step guide for establishing an Ag Pass in a community.

Ag Pass cards are applied for by and distributed to agriculturalists before a disaster. Counties can determine the specific criteria for Ag Pass qualification, but in all cases the application process adequately confirms that the cardholder is a bona fide agricultural owner-operator or employee whose services are essential to providing protection to agricultural assets such as croplands, vineyards, orchards, and livestock. Individuals who acquire an Ag Pass should be key personnel who have a working knowledge of the agricultural property and who have access to irrigation systems, farm equipment, and other essential infrastructure. Individuals with Ag Passes are aware of or have been trained in emergency procedures and understand that their role is to support the agricultural operation, not to fight fire or act as first responders during disaster.

The cards do not necessarily mean that cardholders will be able to pass through road closures to get to their farms or ranches. If there is imminent danger, front-line emergency personnel are empowered to use discretion when it comes to protecting emergency crews and the public from unnecessary exposure to risk. However, when the boundaries of the closure area include agricultural land not deemed at imminent risk, the cards should allow employees access to agricultural property.

\section{ESTABLISHING AN AG PASS IN YOUR COMMUNITY}

\section{What partners need to be involved?}

For successful implementation, Ag Pass programs require partnership from multiple county-based and regional agencies. Agencies that may be interested in participating include but are not limited to

- county-based farm bureaus

- county or regional fire safe councils

- University of California Cooperative Extension (UCCE)

- county agricultural commissioner's offices

- county-based cattlemen's associations

- county offices of emergency services

- county-based animal control or animal services

- Cal Fire and local fire departments

- U.S. Forest Service

- county sheriff's offices

- California Highway Patrol

Very likely, one of these agencies will need to assume the leadership role in the administration and organization of the program (fig. 4). Experience has shown that fire safe councils, farm bureaus, UCCE, and agriculture commissioner's offices are well-positioned to assume that role. In the beginning, administrative duties can be heavy; however, the workload decreases once the program is successfully set 
in motion. Logistical items that will need regular attention include

- handling and processing applications

- designing and generating ID cards

- organizing card renewals

- maintaining communication between agencies

- applying for grants and other sources of funding

\section{How is an Ag Pass program administered?}

Application. To obtain an Ag Pass card, an initial application should be submitted. The application might follow the format used in Ventura County, http://www.cvcfiresafe.org/wp-content/uploads/2017/08/ Card_Request_20141105.pdf. Note that, for employees, this step should be coordinated through the owner or manager of the farm or ranch, who is responsible for designating which key employees should have use of the Ag Pass. Farm or ranch businesses can submit applications on behalf of their employees, but applications should be for individuals and not for businesses or operations. At a minimum, applications should include the applicant's name, contact information, and the agricultural operation's name, location, and contact information. A photograph of the applicant's head and shoulders, similar to a passport photo, should also be included. In order to cover the costs of producing cards and processing applications, it may be necessary to charge a minimal fee or seek grant funding to support the program. A critical step in the application process is for the organizing agency to develop a protocol that confirms the eligibility of individuals or operations that apply for the Ag Pass. This is of particular concern to law enforcement and emergency first responders, whose are responsible for authorizing access behind evacuation lines.

ID Cards. Cards need a standard design that is acceptable to the authorities. At a minimum, required information includes

- the cardholder's photo

- the cardholder's name
- the name of the agricultural operation

- an expiration date

Additional information you might add, if you determine it necessary, includes

- location of agricultural operation (if the operation has multiple locations, use some combination of office, headquarters, and field addresses)

- cardholder identifying information (for example, height, weight, eye color, and so on)

- cardholder's work and mobile phone numbers

- cardholder's driver's license number

- name of issuing agency

- logos of sponsoring agencies

Options for producing cards range from printing on simple card stock (as with business cards) to using a more sophisticated system (for example, with a printer and laminator) that involves detailed images for identification (such as barcodes).

Organizing agencies may choose to include a disclaimer that describes the purpose and limits of the Ag Pass card during disaster. For example, it may be useful to include language emphasizing that the Ag Pass does not guarantee access to closed areas (access is always at the discretion of the public safety agencies or individual officers) and that access, if granted, is taken at the sole risk and responsibility of the cardholder. For example, see the language on the Santa Barbara County press pass shown in figure 3.

Renewals. Cards are typically issued for a definite period of time. As with initial applications, renewals should be coordinated through a farm or ranch's owner, or through a manager responsible for use of the Ag Pass on the property. Annual renewal might ensure that Ag Pass rosters remain up to date, but striving for this kind of accuracy must be balanced with the organizing agency's capacity to handle the renewal workload. At a minimum, the renewal process should occur at least every four years and should include a letter or e-mail sent to the individual cardholder or agricultural operation, requiring confirmation that the information in the Ag Pass database 
is still accurate. One workable compromise might be for Ag Pass cards issued to owners or operators of farms or ranches to remain valid longer than cards issued to farm or ranch employees, who have a higher rate of turnover.

\section{CHALLENGES AND BARRIERS}

\section{Identifying eligibility}

An early challenge in starting an Ag Pass program is developing a protocol for identifying eligible individuals and operations. While the express purpose of the Ag Pass is to support commercial agriculture in the event of a disaster, counties may encounter hobby agriculturalists or animal owners who apply for the Ag Pass. Each county will need to develop clear criteria that determine eligibility, as well as a repeatable process by which to vet applicants. Options for eligibility requirements may include

- cross-referencing records from the county agricultural commissioner, specifically for row crop and orchard operations, who must register their pest and herbicide records with the commissioner's office

- confirming with the county cattlemen's association that an applicant is a commercial livestock operation

- confirming with the county-based farm bureau that an applicant is a commercial farming operation

- cross-referencing farm records maintained by the U.S. Department of Agriculture Farm Service Agency

- requesting a redacted "Schedule F" tax form to establish that an individual or operation has agricultural taxable income

- requesting the farm or ranch's Assessors Parcel Number (APN) to cross-reference with county records to confirm agricultural zoning status

- Requesting land leasing documentation for a farm or ranch

\section{Agricultural operations with multiple locations}

The intention of the Ag Pass is to allow commercial agricultural owner-operators or employees access through areas otherwise closed to the public during a disaster for the express purpose of tending to agricultural matters on their farms or ranches. In an effort to limit the Ag Pass's use to just this activity, you may decide to include the agricultural operation's address as identifying information on the Ag Pass card itself so that personnel at road closures can determine if the Ag Pass cardholder should enter the restricted area. One potential complication, however, is that it is not uncommon for a farm or ranch in California to have multiple production sites within a county. In designing the card, you should consider how this should be addressed. You may choose to include all addresses of production sites. Alternatively, you may choose to include no production site addresses to allow for maximum flexibility during disaster, and trust that cardholders and emergency response personnel on the ground will use good judgment.

\section{Mutual aid}

Agriculturalists frequently depend upon support from other farmers or ranchers during a disaster. This may be particularly true during livestock evacuations, when large numbers of animals need to be relocated quickly. A sponsoring agency should consider if the Ag Pass program can explicitly allow and support this kind of activity, and in what manner. Will all who seek access past road closures during a disaster be required to hold Ag Pass documentation? Or would it be acceptable for one Ag Pass holder to "shepherd" others through road closures to utilize their support? If an Ag Pass is required for all who seek access, it may behoove an agriculturalist who anticipates relying on others' support during disaster to request that they apply for Ag Passes themselves.

\section{Communication and outreach}

After the initial hurdle of establishing county support for the Ag Pass, the single greatest challenge to ensuring a successful program 
is maintaining regular and consistent communication among the agencies involved, particularly during disasters. The Ag Pass only works if all participating agencies, at all levels, know about and buy into the program.

Before a disaster. Generally speaking, it is important to provide annual reminders to the county about the existence of and procedures surrounding the Ag Pass. While the structure of every county's government is different, as is the structure of counties' disaster response teams, entities with which you should remain in regular contact likely include

- county board of supervisors

- county planning and development office

- county sheriff

- county fire department and/or Cal Fire

- county agricultural commissioner

- California Highway Patrol

- city police and fire departments

- county office of emergency services

Commonly, counties will have an annual or semiannual meeting or conference call, frequently in the spring before fire season (June to November), in which all the agencies listed above gather to discuss disaster protocols. These meetings make an excellent opportunity to remind people how the Ag Pass program works. Making annual or semiannual presentations to the county sheriff's office and the regional California Highway Patrol office is especially useful, as these agencies are typically responsible for managing road closures during a disaster.

During a disaster. It is critical that you establish procedures for, and identify advocates of, the Ag Pass before a disaster so that the Ag Pass can be incorporated into the management effort during a disaster. Specifically, creating a direct line of communication with individuals or agencies that will be decision makers during a disaster is especially important. In the case of wildfire, for example, fire suppression efforts are organized at an incident command post. During larger fires, the command post is frequently led by fire professionals from out of town, but county-based departments are included in daily briefings. If you can identify an Ag Pass advocate who will be present at those briefings, such as a county supervisor or the county agricultural commissioner, that individual will be able to explain the county-based Ag Pass program to the command post and coordinate daily decisions about which areas of the county will be closed to the public but open to Ag Pass holders. Having access to the command post during a disaster, or decision makers at an equivalent level, means that officers or other first responders at checkpoints throughout the county will receive the proper authorization to allow $\mathrm{Ag}$ Pass holders to pass into restricted areas.

\section{Health and safety of farm workers}

The purpose of an Ag Pass program is certainly not to put vulnerable communities, which can often include farm workers, at risk. Given that such personnel may be "on the front lines" and potentially exposed to greater danger than others who have evacuated, each farm or ranch should consider workers' potential need to shelter in place during an emergency. Farms or ranches should therefore identify safety zones or fire-resistant structures as local refuges (https://firesafemendocino.org/creating-a-safety-zone-for-use-in-a-wildfire-emergency/; https://www.nwcg.gov/committee/6mfs/safetyzones1-lces). Similarly, workers using an Ag Pass should be provided the required personal protective equipment (for example, respiratory and heat protection) for whatever hazards they may encounter (https://www.dhs.gov/sites/ default/files/publications/Wild-FF-PPE-

SG_0614-508.pdf; https://files.dnr.state.mn.us/ forestry/wildfire/rxfire/protective_equip.pdf; https://www.dir.ca.gov/dosh/wildfire/Protective-Equipment-During-Fire-Cleanup.html). To this end, the Ag Pass-sponsoring agency may decide that a farm or ranch can only qualify for the program if it first produces an emergency plan. Emergency plans should be specific to the people and property in question. They could be simple-for example, a map showing access roads, water points, and refuges (fig. 5). Or they might be complex-for example, a written document describing safety and evacuation protocols. An Ag Pass-sponsoring agency may 


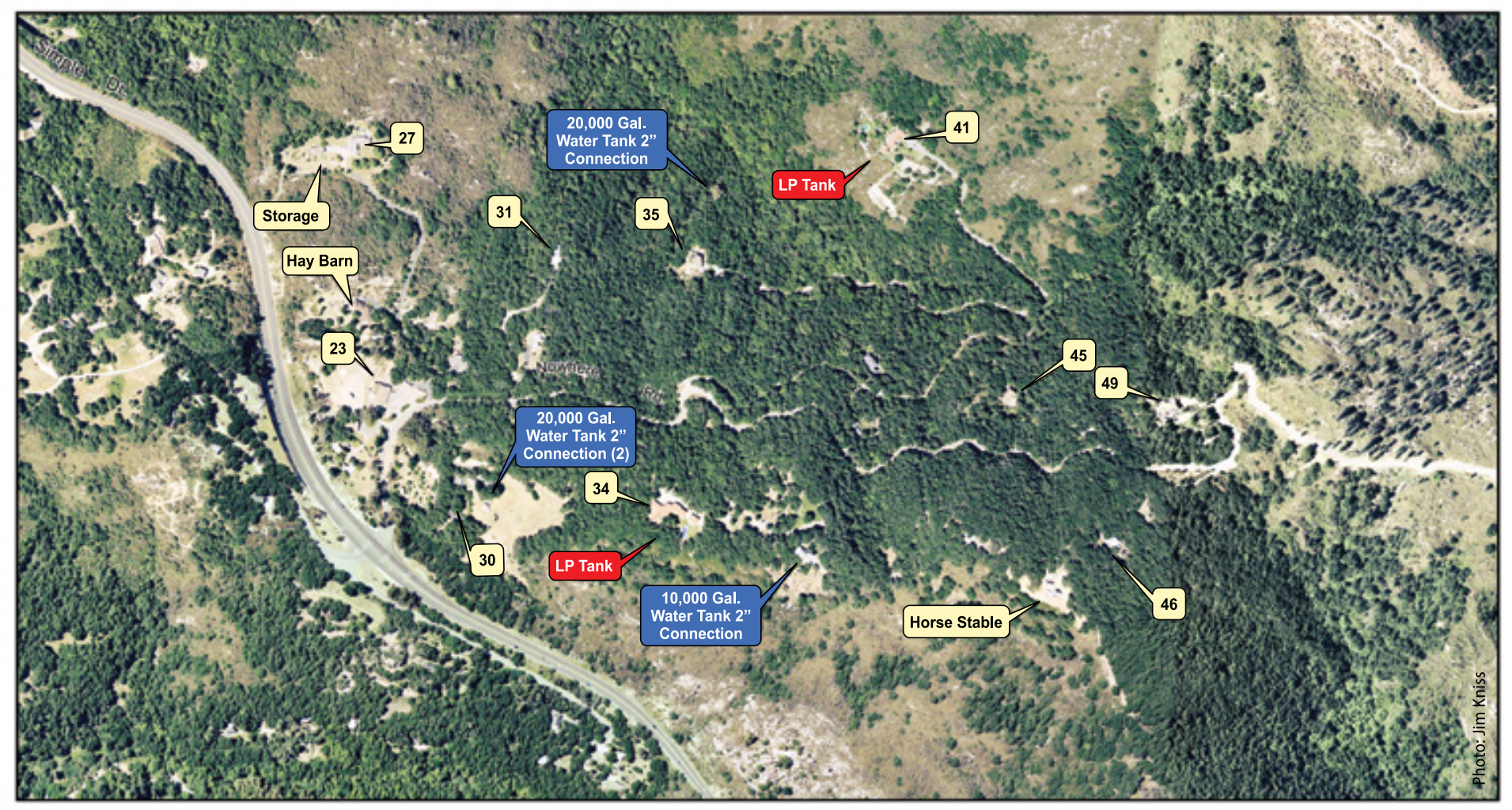

\begin{tabular}{|c|c|c|c|c|c|}
\hline $\int_{\text {Fire }}$ & $\begin{array}{c}\text { Ranch Plan } \\
\text { Rancho to Nowhere } \\
\text { Burnsville, USA }\end{array}$ & $\begin{array}{l}\text { Water Tank } \\
\text { Fuel Storage } \\
\text { Gate }\end{array}$ & $\begin{array}{l}\text { (1) Water Source } \\
\text { (1) Helispot } \\
\text { (9taging }\end{array}$ & 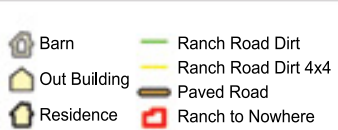 & Ranch Data from July 4, 2016 \\
\hline COUNCIL & $\begin{array}{llll}0 & 250 & 500 & 1.000 \\
0 & \quad 250 t\end{array}$ & & & & $\begin{array}{l}\text { Ranch Datat from July 4, } 2016 \\
\text { Aerial Photography from Fall } 2014\end{array}$ \\
\hline
\end{tabular}

Figure 5. Example ranch plan map. Source: Veterans Emergency Technical Services/Central Ventura Fire Safe Council.

choose to have these plans vetted by local fire authorities before they are put into action.

Additionally, operators and employers should make an effort to understand how the Ag Pass program - and by extension, access to areas closed to the public during a disastermay affect the details of their property liability insurance, vehicle or equipment insurance, and worker's compensation requirements. Instances have been documented throughout the state of insurance companies refusing to extend coverage to persons, vehicles, and equipment during disaster management and recovery efforts.

Another consideration to ensure the health and safety of Ag Pass holders during a disaster is to establish access protocols and requirements. Protocols may include formal check-in and check-out procedures-with either the incident command post or the Ag Pass-sponsoring agency. They may also include a stipulation that access under the Ag Pass will only be granted to groups of at least two qualifying cardholders so that an individual is never in a disaster area alone.

Training. It may be good practice to explore how the Ag Pass could formalize onetime or ongoing training and education for cardholders. Broadly, training efforts might be organized by the Ag Pass-sponsoring agency and address the health and safety of cardholders and general best practices during disaster-or organized by an individual farm or ranch for its employees and managers and address protocols specific to the operation. In either case, training and continuing education might be an excellent opportunity to demonstrate to emergency services and law enforcement agencies within the community that due diligence is being conducted. It is important to note that many disaster-related volunteer programs require registration and certification, often through California's Disaster Service Worker Volunteer Program, https://www.caloes.ca.gov/governments-tribal/ 
plan-prepare/disaster-service-worker-volunteer-program. While extensive training could strengthen an Ag Pass program, requiring such training could limit participation. Regardless, training or certification may be additional methods by which communities vet eligibility to participate in an Ag Pass program.

Scale. Another challenge will be determining the appropriate scale of the Ag Pass program, as participating agencies may feel uncomfortable if an unlimited number of passes can be issued. Potential solutions to this challenge include

- limiting the number of Ag Passes that can be issued to any one agricultural operation

- limiting qualified applicants to owner/operators or managers of farms or ranches

- limiting eligible farms and ranches geographically (for example, farms or ranches in the wildland-urban interface are more likely to be threatened by wildfire than are farms and ranches in valley bottoms, in or near urban areas, or on coastal plains)

Addressing these issues and reaching a shared understanding among participating agencies is essential.

\section{Roadblock protocols}

Increasingly, public safety agencies are discussing the most effective manner to determine evacuation areas and impose road closures in the event of a disaster. Directives may vary from one county to another. They may vary depending upon the type of disaster (for example, fire or flood). They may change from year to year. It is therefore critical that designers of any Ag Pass program understand and revisit current local and regional protocols regarding evacuation areas and road closures. The program should be designed to fit within those directives. Important details to understand in your local and regional context include whether road closures are "hard" (closed to the public) or "soft" (open to residents) and whether "mandatory evacuations" or "evacuation warnings" have been issued. Methods for repopulating evacuation areas are also important to understand.
Additionally, individual agricultural owner-operators and managers who acquire an Ag Pass should be expected to research and understand the relevant evacuation zones and protocols near their farms or ranches. Although the Ag Pass offers the potential for special treatment during a disaster, Ag Pass holders should always heed and respect evacuation warnings or orders unless they are specifically exempted through the Ag Pass process.

\section{CASE STUDY: VENTURA COUNTY}

Beginning no later than the 1985 Wheeler Fire, which significantly affected citrus and avocado orchards in the Ojai Valley, members of the agricultural community and fire suppression agencies in Ventura County broadly discussed establishing some mechanism that could allow for greater protection of agricultural assets during wildfire. It wasn't until the mid-2000s, however, that the Ventura County Agricultural Worker ID Program was designed and implemented. The concept was simple: to distribute an identifying card that would allow agricultural workers to pass through road closures in order to reach their farms or ranches if the area was no longer in imminent danger. Initially, the program was administered by the Ventura County Farm Bureau. The Central Ventura County Fire Safe Council (FSC), when it was established in 2010, took over responsibility for program administration.

Early cards were printed on a heavy, blue cardstock; included space for the cardholder's name, address, and identifying information (height, weight, hair color, and so on); and were passed out blank to participating farms or ranches. The cardholder or farm or ranch manager would fill in the information by hand. As a result, there was no standardized procedure or centralized record keeping when the program was established in 2010.

In 2012, a grant to the FSC from a local philanthropic organization allowed for the expansion and formalization of the program. The FSC purchased a laptop, card printer, and ID software, which allowed it to redistribute cards (fig. 6) and maintain records of cardholders. To promote participation in the program, the FSC 


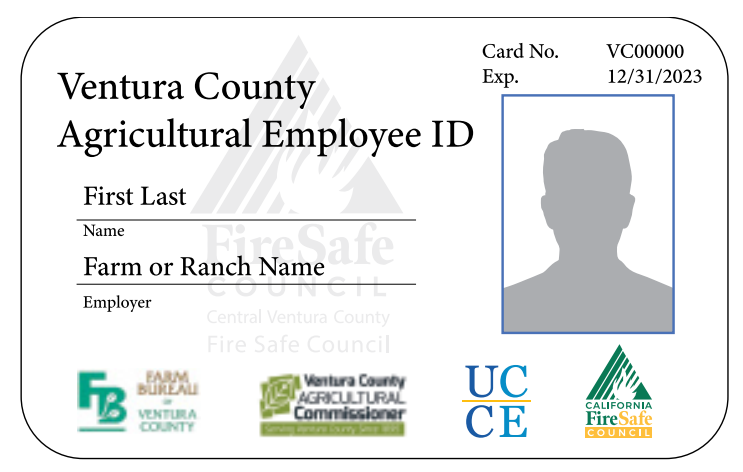

Ranch Address (primary)

Additional Ranch Address (optimal):

Additional Ranch Address (optimal):

At the discretion of a public safety member or their designee, this card when accompanied by valid photo identification may be used to gain needed and legitimate access to restricted areas during emergency road closure. Said access if granted is taken at the sole risk and responsibility of the card holder and employer.

Central Ventura Fire Safe Counci

www.cvcfiresafe.org

Figure 6. A design proposed in summer of 2019 for an "Ag Pass" identification card in Ventura County. Source: Central Ventura Fire Safe Council

relied on articles in the Farm Bureau newsletter and word of mouth.

In late 2014, the FSC met with representatives from the Ventura County Agricultural Commissioner's Office and Office of Emergency Services, who expressed some concern that the program had no formal vetting process for applicants. The FSC then developed the process it uses today: when an application is received, a request is submitted by the FSC to the Agricultural Commissioner's Office to confirm the farm/ranch name and location from the County's Pesticide Applicator Permit database. The Commissioner's Office then provides a letter to the FSC to be stored in the applicant's file.

Concurrent with this more formalized vetting process, the FSC worked with participating Ag Pass holders to develop "ranch plans" (see fig. 5). In developing these ranch plans, farms and ranches at a minimum produced detailed maps that showed access roads (many of which did not show up on maps available to County personnel), agricultural fields, agricultural buildings, hazardous materials, engine turnaround areas, bridge loading, other critical infrastructure, and points of water storage and access. The FSC and the Ventura County Fire Department have made efforts to provide Ventura County agencies with immediate digital access to these maps during disasters (though not all maps are available).

By 2017, the Ventura County Ag Pass database had grown to over 400 cardholders. However, emergency personnel (California Highway Patrol, as well as Ventura County's Fire Department, Office of Emergency Services, Sheriff's Office, and so on) still lacked awareness of the program, and no process had been established for providing regular briefings about the program. This fact was made frustratingly clear during the Thomas Fire, which burned through, or close to, many farms and ranches for three weeks in December 2017. The fire was the largest wildfire in California history at the time, so emergency personnel were mobilized from around California and neighboring states. But because the FSC had not adequately educated local emergency personnel before the fire and had no protocols in place for educating emergency personnel from outside the area during the fire, farmers and ranchers in the county reported mixed success using their Ag Pass cards. Those who were turned away at road closures reported agricultural losses that could have been avoided if they had been able to access their propertiesfor example, trees were lost in orchards because of a lack of irrigation and livestock died for lack of stock water or because veterinary care for burned animals could not be provided (fig. 7). But some farmers and ranchers were able to obtain access with the card as intended, to great positive effect. One avocado rancher in eastern Ventura County, an early adopter of the Ag Pass program, was able to gain access to his ranch, along with key employees, through successful use of their cards. He reports that using the Ag Pass during and immediately after the Thomas Fire allowed him to turn on irrigation as the fire approached, substantially reducing losses in his orchard, and to meaningfully assist fire suppression personnel in locating critical infrastructure on his ranch (including roads, water sources available for fighting fire, and safety zones for firefighting personnel). 


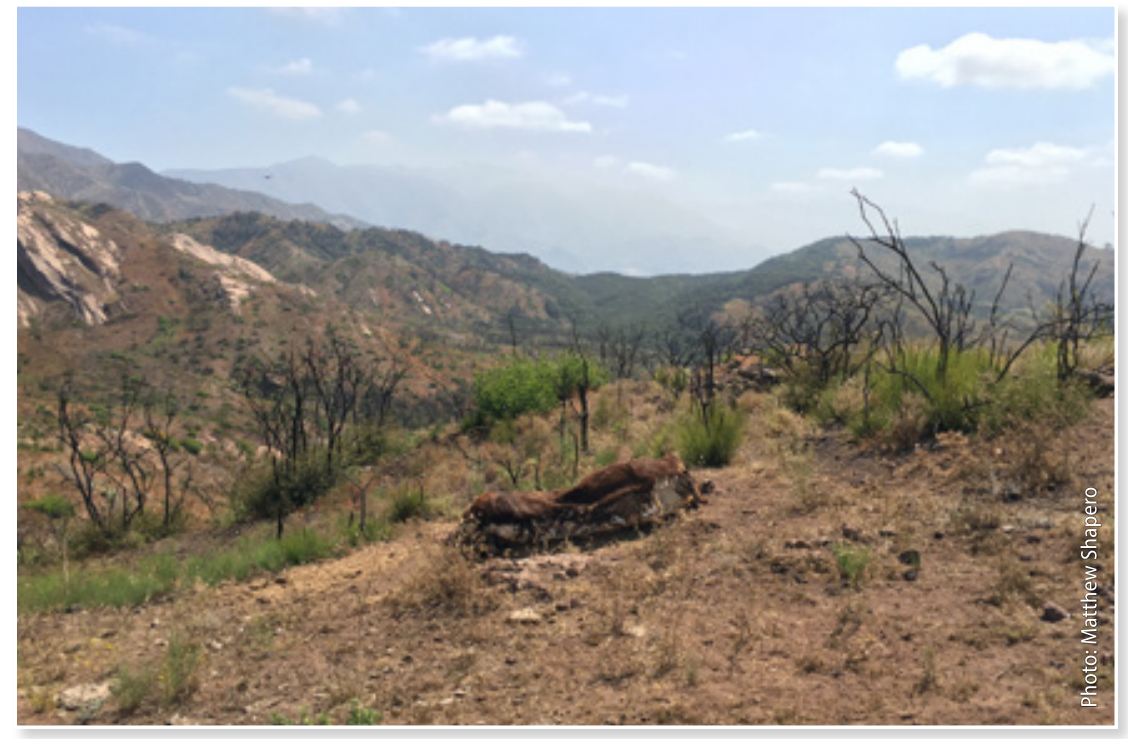

Figure 7. Carcass of burned livestock lost during the Thomas Fire in the Ojai Valley in December of 2017; photograph was taken in summer of 2018.

Stakeholders in Ventura County are committed to continuously working to improve cooperation around the Ag Pass. Areas of focus include

- Ag Pass cards that are designed in accordance with law enforcement agencies' requirements

- guidance documents that codify how information about the Ag Pass is communicated to officials and emergency personnel at the Incident Command Post during disaster, and

- more formalized and regular communication and outreach efforts to facilitate implementation during a disaster

Overall, participating agencies and agriculturalists are pleased with the program's direction, effectiveness, and promise.

\section{SUMMARY}

Disasters in general, and wildfire in particular-in addition to their serious impact on lives and residential property-present critical logistical challenges to agricultural operations in California. While closing areas of a county to the general public is a necessary component of suppressing wildfire and ensuring public safety, there are instances in which prolonged road closures may avoidably harm crops, orchards, and livestock. Innovative approaches to this problem, reflecting the wider trend of adapting to and learning from wildfire-related experiences (Abrams et al. 2015), have resulted in the Ag Pass concept. Ag Pass programs provide a way to mitigate some of wildfire's negative impacts on agriculture while also ensuring general public safety.

There is great potential for establishing the Ag Pass program statewide. Protocols for firefighting and evacuation enforcement, however, are likely to vary across counties in California, so this document is intended as a best-practices guide; any successful Ag Pass program will need to be tailored to the specific characteristics and constraints of a specific community. Ultimately, the success of an Ag Pass program will depend upon ongoing interagency cooperation and communication.

\section{Acknowledgments}

Figure 3 is provided courtesy of the Burn Cycle Project, https://burncycleproject.com/.

Figure 6 is provided courtesy of the Ventura County Fire Safe Council, http://www. cvcfiresafe.org/ranch-plans/.

\section{REFERENCES}

Abrams, J.B., M. Knapp, T.B. Paveglio, A. Ellison, C. Moseley, M. Nielsen-Pincus, and M.S. Carroll. 2015. Re-envisioning communitywildfire relations in the U.S. West as adaptive governance. Ecology and Society 20(3):34. https://doi.org/10.5751/ES-07848-200334

Aquilué, N., M.J. Fortin, C. Messier, and L. Brotons. 2019. The potential of agricultural conversion to shape forest fire regimes in Mediterranean landscapes. Ecosystems 23:1-18. https://doi.org/10.1007/s10021-01900385-7

Chong, H.H., and M.T. Cleary. 2012. Smoke taint aroma assessment in 2008 California grape harvest. In M.C. Qian and T.H. Shellhammer, eds., Flavor chemistry of wine and other alcoholic beverages. Washington: American Chemical Society. 67-79. 
Krstic, M.P., D.L. Johnson, and M.J. Herderich. 2015. Review of smoke taint in wine: smokederived volatile phenols and their glycosidic metabolites in grapes and vines as biomarkers for smoke exposure and their role in the sensory perception of smoke taint. Australian Journal of Grape and Wine Research 21(S1):537-553. https://doi.org/10.1111/ ajgw.12183

Moritz, M.A., E. Batllori, R.A. Bradstock, A.M. Gill, J. Handmer, P.F. Hessburg, J. Leonard, S. McCaffrey, D.C. Odion, T. Schoennagel, and A.D. Syphard. 2014. Learning to coexist with wildfire. Nature 515(7525):58-66. https://doi. org/10.1038/nature 13946

Nader, G., Z. Henkin, E. Smith, R. Ingram, and N. Narvaez. 2007. Planned herbivory in the management of wildfire fuels. Rangelands 29(5):18-24. https://doi.org/10.2458/azu_ rangelands_v29i5_nade

Radeloff, V.C., R.B. Hammer, S.I. Stewart, J.S. Fried, S.S. Holcomb, and J.F. McKeefry. 2005. The wildland-urban interface in the United States. Ecological applications 15(3):799-805. https://doi.org/10.1890/04-1413

Radeloff, V.C., D.P. Helmers, H.A. Kramer, M.H. Mockrin, P.M. Alexandre, A. Bar-Massada, V. Butsic, T.J. Hawbaker, S. Martinuzzi, A.D. Syphard, and S.I. Stewart. 2018. Rapid growth of the U.S. wildland-urban interface raises wildfire risk. Proceedings of the National Academy of Sciences 115(13):3314-3319. https://doi.org/10.1073/pnas.1718850115

Schoennagel, T., J.K. Balch, H. Brenkert-Smith, P.E. Dennison, B.J. Harvey, M.A. Krawchuk, N. Mietkiewicz, P. Morgan, M.A. Moritz, R. Rasker, M.G. Turner, and C. Whitlock. 2017. Adapt to more wildfire in western North American forests as climate changes. Proceedings of the National Academy of Sciences 114(18):4582-4590. https://doi. org/10.1073/pnas.1617464114

\section{FOR FURTHER INFORMATION}

To order or obtain ANR publications and other products, visit the ANR Communication Services online catalog at http:// anrcatalog.ucanr.edu/ or phone 1-800-994-8849. You can also place orders by mail or FAX, or request a printed catalog of our products from

University of California

Agriculture and Natural Resources

Communication Services

2801 Second Street

Davis, CA 95618
Telephone 1-800-994-8849

E-mail: anrcatalog@ucanr.edu

(C2020 The Regents of the University of California. This work is licensed under the Creative Commons AttributionNonCommercial-NoDerivatives 4. 0 International License. To view a copy of this license, visit http://creativecommons.org/ licenses/by-nc-nd/4.0/ or send a letter to Creative Commons, PO Box 1866, Mountain View, CA 94042, USA.

Publication 8685

ISBN-13: 978-1-62711-145-4

The University of California, Division of Agriculture and Natural Resources (UC ANR) prohibits discrimination against or harassment of any person in any of its programs or activities on the basis of race, color, national origin, religion, sex, gender, gender expression, gender identity, pregnancy (which includes pregnancy, childbirth, and medical conditions related to pregnancy or childbirth), physical or mental disability, medical condition (cancer-related or genetic characteristics), genetic information (including family medical history), ancestry, marital status, age, sexual orientation, citizenship, status as a protected veteran or service in the uniformed services (as defined by the Uniformed Services Employment and Reemployment Rights Act of 1994 [USERRA]), as well as state military and naval service.

UC ANR policy prohibits retaliation against any employee or person in any of its programs or activities for bringing a complaint of discrimination or harassment. UC ANR policy also prohibits retaliation against a person who assists someone with a complaint of discrimination or harassment, or participates in any manner in an investigation or resolution of a complaint of discrimination or harassment. Retaliation includes threats, intimidation, reprisals, and/or adverse actions related to any of its programs or activities.

UC ANR is an Equal Opportunity/Affirmative Action Employer. All qualified applicants will receive consideration for employment and/or participation in any of its programs or activities without regard to race, color, religion, sex, national origin, disability, age or protected veteran status.

University policy is intended to be consistent with the provisions of applicable State and Federal laws.

Inquiries regarding the University's equal employment opportunity policies may be directed to: Affirmative Action Contact and Title IX Officer, University of California, Agriculture and Natural Resources, 2801 Second Street, Davis, CA 95618, (530) 750-1397. Email: titleixdiscrimination@ ucanr.edu. Website: http://ucanr.edu/sites/anrstaff/Diversity/ Affirmative_Action/.

An electronic copy of this publication can be found at the ANR Communication Services catalog website, https://anrcatalog. ucanr.edu/.

This publication has been anonymously peer reviewed for UC technical accuracy by University of California PEER scientists and other qualified professionals. REVIEWED This review process was managed by UC ANR Associate Editor for Animal Science and Rangeland Ecology and Management Julie Finzel.

web-12/20-LC/SO 